Published in final edited form as:

Curr Opin Struct Biol. 2007 October ; 17(5): 513-520.

\title{
Functions of cell surface galectin-glycoprotein lattices
}

\author{
Gabriel A. Rabinovich ${ }^{\star}$, , Marta A. Toscano*, Shawn S. Jackson $\ddagger$, and Gerardo R. Vasta ${ }^{\star}$ \\ * Department.of Immunopathology. Instituto de Biología y Medicina Experimental IBYME, CONICET. \\ C1428ADN, Buenos Aires, Argentina \\ † Departamento de Química Biológica. Facultad de Ciencias Exactas y Naturales, Universidad de Buenos \\ Aires. C1428ADN, Buenos Aires, Argentina \\ $\ddagger$ Center of Marine Biotechnology, University of Maryland Biotechnology Institute, Baltimore, Maryland \\ 21202, USA
}

\begin{abstract}
Programmed remodeling of cell surface glycans by the sequential action of specific glycosyltransferases, can control biological processes by generating or masking ligands for endogenous lectins. Galectins, a family of animal lectins with affinity for $\beta$-galactosides, can form multivalent complexes with cell surface glycoconjugates and deliver a variety of intracellular signals to modulate cell activation, differentiation, and survival. Recent efforts involving genetic or biochemical manipulation of $O$ - and $\mathrm{N}$-glycosylation pathways, as well as blockade of the synthesis of endogenous galectins, have illuminated essential roles for galectin-glycoprotein lattices in the control of biological processes including receptor turnover and endocytosis, host-pathogen interactions and immune cell activation and homeostasis.
\end{abstract}

\section{Keywords}

galectins; galectin-glycoprotein lattices; receptor turnover; immunity; inflammation

\section{Introduction}

For many systems, the clustering of protein receptors and ligands is required for optimal transmission of signals into a cell. The thermodynamically favorable assembly of ordered arrays of lectins and saccharides on the cell surface may thus be integral to cellular signaling and adhesion [1]. Lectin multivalency enables recognition of multiple binding partners, allowing these glycan-binding proteins to play leading roles in signal transduction in different biological processes as well as in cell-cell and cell-pathogen interactions [2-4].

Galectins are a family of soluble lectins that bind $\beta$-galactoside-containing glycans and are defined by a conserved carbohydrate recognition domain (CRD) and a common structural fold [2-4]. Among the various lectin types, galectins are probably the most conserved and ubiquitous family, with members identified in most animal taxa examined so far [4]. As many as fifteen galectins have been identified in mammals and proposed to mediate diverse biological processes involved in the regulation of innate and adaptive immune responses, such as cell

Corresponding author: Dr. Gabriel A. Rabinovich, Instituto de Biología y Medicina Experimental IBYME, CONICET. Vuelta de Obligado 2490 (C1428ADN) Buenos Aires, Argentina, Tel: +54-11-4783-2869, E-mail: gabyrabi@ ciudad.com.ar.

Publisher's Disclaimer: This is a PDF file of an unedited manuscript that has been accepted for publication. As a service to our customers we are providing this early version of the manuscript. The manuscript will undergo copyediting, typesetting, and review of the resulting proof before it is published in its final citable form. Please note that during the production process errors may be discovered which could affect the content, and all legal disclaimers that apply to the journal pertain. 
activation, differentiation, cytokine secretion and apoptosis [5,6]. Here we discuss recent findings on the biochemistry of galectin-glycoprotein lattices and their functional relevance in the control of receptor endocytosis, host-pathogen interactions and activation and homeostasis of immune cells.

\section{Biochemical aspects of galectin-glycoprotein lattices formation}

Lectin-monosaccharide interactions are relatively weak (dissociation constants $\sim 10^{-4} \mathrm{M}$ ), with two to five hydrogen bonds complemented by hydrophobic and van der Waals interactions $[4,5,7]$. Galectins preferentially bind $\beta$-galactoside-containing glycans comprised of repeating units of $N$-acetyllactosamine (Gal $\beta 1,4 \mathrm{GlcNAc}$; LacNAc), either as disaccharide units at the termini of complex $\mathrm{N}$-glycans, or as repeating units in a poly- $N$-acetyllactosamine chain on $\mathrm{N}$ - or $O$-glycans [5,7,8]. Galectin binding affinities to complex $N$-glycans are proportional to their LacNAc content and to their GlcNAc branching [5,7-11].

Lattice formation by galectins requires multivalent oligomerization to attain stability and biologic functionality [5]. Based on structural features, galectins have been classified into three types: proto, chimera, and tandem-repeat [4]. Proto-type galectins contain one CRD per subunit and typically dimerize through noncovalent interactions to create functionally bivalent lectins. Proto-type galectin-1 is a dimer in solution and crystallizes as a dimer in cross-linked complexes with a divalent oligosaccharide[12]. The presence of more than one CRD in a galectin-1 homodimer makes it well-suited for mediating cell adhesion, eliciting signaling, and forming lattices [3,5]. The chimera-type galectin-3 has a C-terminal CRD similar to the prototype, but exhibits an $\mathrm{N}$-terminal domain that is responsible for interactions between subunits, facilitating its oligomerization [3]. Galectin-3 monomers are in equilibrium with higher order oligomers in solution, and galectin-3 precipitates as a pentamer with multivalent oligosaccharides [13]. This lectin binds to multi-glycosylated proteins with positive cooperativity, suggesting that galectin-3 monomers, after ligand binding, recruit additional lectin molecules to form a complex of multivalent interactions $[5,13]$. The biologic functions attributed to galectin-3 are thus likely to depend upon both ligand cross-linking and oligomerization [6,14-17]. The tandem-repeat type galectins have two CRDs connected by a linker peptide and, thus are bivalent, although the two CRDs may be able to recognize different saccharide ligands [6] (Figure 1).

Glycoproteins often bear multiple copies of the saccharide ligands that are recognized by galectins [18]. While galectin binding to a single saccharide ligand is typically a low-affinity interaction (association constants $\sim 10^{4} \mathrm{M}^{-1}$ ), the multivalent nature of galectin-saccharide interactions results in high overall avidity (association constants $\sim 10^{6} \mathrm{M}^{-1}$ ) [5,9]. This multivalency also allows the formation of lectin-carbohydrate lattices. Both in solution and on the cell surface, multivalent galectins selectively cross-link a single species of glycoprotein to form homogeneous lectin-carbohydrate lattices $[5,17,19]$.

The ability of galectins to reorganize membrane glycoproteins into lipid raft microdomains suggests that multivalent lectin-saccharide interactions occur preferentially in these microdomains [5]. In this regard, the ganglioside $\mathrm{GM}_{1}$ is able to organize microdomains into raft-like structures and is a prominent glycolipid headgroup in such rafts. Galectin-1 binds the $\mathrm{GM}_{1}$ pentasaccharide glycan and these interactions may represent a mechanism by which galectins organize lipid rafts [20]. Since lipid rafts are considered essential for assembling signal transduction components at the plasma membrane [1], association of galectins with lipid rafts is likely to be important for galectin-mediated signaling events. 


\section{Biological aspects of galectin-glycoprotein lattices}

\section{Galectins and receptor turnover}

Lattice formation following the binding of complex $\mathrm{N}$-glycans to galectins effectively traps glycoprotein receptors at the cell surface, preventing their endocytosis. Thus, interactions between $\mathrm{N}$-glycans and galectins can regulate the distribution of cell surface receptors as well as the cell's responsiveness to receptor agonists [11]. Recently, Dennis and colleagues described a link among $N$-glycan multiplicity, $N$-glycan branching kinetics, integration of nutrient metabolism and changes between cell growth and arrest [10]. The authors described that $N$-branching in the Golgi is sensitive to hexosamine flux for its production of complex $\mathrm{N}$-glycans. Whereas arrest-promoting receptors (e.g., e.g., TGFßR and CTLA-4) have few $N$ glycosylation sites and show a 'switch-like' responses to hexosamine concentrations, growthpromoting receptors (e.g., EGFR, IGFR, FGFR, and PDGFR) with high numbers of $N$-glycans exhibit hyperbolic responses to hexosamine [10]. Therefore, increased nutrient flux stimulated by growth-promoting receptors, will ultimately activate cellular arrest and differentiation programs by increasing surface levels of glycoreceptors with low numbers of $N$-glycans. The authors report that increasing UDP-GlcNAc leads to increased branching of $N$-glycans, increased receptor association with cell surface galectin-3 and enhanced signaling [10]. Thus, galectin-carbohydrate lattices can regulate the decision between cell growth and arrest by regulating receptor turnover (Figure 2).

A second biological example of galectin-mediated control over receptor endocytosis is the galectin-9-glucose transporter 2 (GLUT-2) system. All vertebrate glucose transporters have a single conserved $N$-glycan site. Cell-type and glycoprotein-specific $N$-glycans attached by $N$ acetylglucosaminyltransferase IVa (GlcNAcT-IVa) are needed to maintain the glucose transporter GLUT-2 on the surface of pancreatic $\beta$ cells [21]. GlcNAcT-IVa-dependent glycosylation increases the cell-surface half-life of GLUT-2, suggesting that interactions involving the GLUT-2 $N$-glycan structure may suppress its endocytosis. Since GLUT-2 and galectin-9 normally co-localize in pancreatic $\beta$ cells in a GlcNAcT-IVa-dependent manner [21], it is surmised that galectin-9 acts to retain glucose receptors on the cell surface.

Also by interfering with receptor endocytosis, $N$-acetylglucosaminyltransferase $\mathrm{V}$ (GlcNAcTV) expression-dependent galectin lattices, such as galectin-3-TGF $\beta R$ lattices, maintain growthfactor receptor densities at levels that promote invasive phenotypes in transformed cells [11, 22]. In addition, galectin-3 interactions with GlcNAcT-V-modified $N$-glycans stimulate $\alpha_{5} \beta_{1}$ integrin activation, focal adhesion remodeling and phosphatidylinositol 3-kinase activation, thus promoting tumor cell motility [23].

\section{Galectin-carbohydrate lattices in host-pathogen interactions}

Galectins interact with $\beta$-galactoside-enriched glycoconjugates present in several pathogens [24-26]. While the nature of these interactions is not well-characterized, galectin oligomerization and/or lattice formation are likely to play a role.

It has been demonstrated that galectin-1 inhibits envelope-mediated cell-cell fusion of some paramyxoviruses by binding to specific $N$-glycans on viral glycoproteins and inducing its oligomerization [27]. However, galectin-1 can also promote human immunodeficiency virus infectivity by stabilizing viral attachment to host cells and cross-linking viral glycoproteins with the target cells [28].

Specific interactions have been described between galectin-3 and -9 and the intracellular protozoan Leishmania. Galectin-3 binds the lipophosphoglycan (LPG) of L. major [26]. This binding leads to the proteolytic removal of the galectin- $3 \mathrm{~N}$-terminal domain, preventing oligomerization. In this way, L. major destroys galectin-3 lattice formation, leading to a 
decreased threshold for signal transduction [26]. Galectin-9 also recognizes $L$. major by binding to LPG and promotes L. major-macrophage interactions, which may be critical for the clinical outcome of leishmaniasis [25].

Recently, a novel galectin type with four CRDs was discovered in the eastern oyster, Crassostrea virginica. This molecule binds to endogenous ligands at the surface of the oyster's phagocytic cells and recognizes exogenous carbohydrate ligands on microbial pathogens and phytoplankton components [29]. Although this novel galectin binds $\beta$-galactosyl residues, it exhibits broader saccharide specificity than mammalian galectins, which may confer upon this oyster galectin biological functions involved in immune recognition, as well as in feeding and intracellular digestion [29]. Thus galectin-carbohydrate lattices may have evolved to ensure host-pathogen interactions during the initiation and resolution of microbial infections.

\section{Galectin-glycoprotein lattices in innate immunity}

Galectin-carbohydrate lattices may also modulate the biology of innate immune cells at inflammatory foci $[6,15,16]$. Galectin-3-mediated ligand clustering triggers neutrophils to phagocytose, produce reactive oxygen species, release proteases, and secrete interleukin (IL)-8 $[15,16,30]$. In addition, galectin-3 induces mast cell degranulation: recent studies have revealed a critical role for this protein in mast cell function since galectin-3-deficient mast cells show reduced histamine release and IL-4 secretion [14].

Also critical for innate immune responses, macrophages require GlcNAcT-V-dependent galectin-glycoprotein lattice formation to maintain sufficient cell-surface cytokine receptor density to drive motility and phagocytosis [11]. Moreover, by interacting with specific saccharide ligands, galectin-1 differentially regulates Fc $\gamma$ receptor I-dependent phagocytosis and inhibits major histocompatibility complex (MHC)-II-dependent antigen presentation by monocytes/macrophages [31].

Recently, fluorescence resonance energy transfer (FRET) was employed to visualize physiological galectin-3 oligomerization on the surface of neutrophils and endothelial cells [15]. Removal of the $N$-terminal domain of galectin- 3 by proteolytic cleavage prevented oligomerization. These studies further suggested that galectin-3 lattices are robust, stable, and rigid, with slow lateral movement on the surface of cells, and could thus easily restrict receptor clustering and modulate cell signaling [15].

\section{Galectin-glycoprotein lattices in T cell functions}

Cross-linkage of T-cell surface receptors by galectins can trigger different transmembrane signaling events through which diverse processes such as survival, activation, and cytokine secretion are modulated [6].

The T-cell receptor (TCR) $\alpha / \beta$ is decorated by GlcNAcT-V -modified $N$-glycans which restrict nonspecific TCR aggregation through binding to galectins. Multivalent galectin-3-TCR complex lattices limit TCR clustering at the immune synapse by restricting lateral TCR movement within the plane of the membrane, thus increasing agonist threshold for TCR signaling $[32,33]$. Conversely, deficiency in GlcNAcT-V lowers T-cell activation threshold by enabling TCR clustering and signaling characterized by increased TCR-dependent tyrosine phosphorylation and proliferation $[32,33]$.

The authors recently extended their observations, showing that $\beta 1,6 \mathrm{GlcNAc}$-branched $\mathrm{N}$ glycans on $\mathrm{T}$ cells are regulated by the nutrient environment and metabolite supply of the hexosamine pathway. Thus the production of high affinity ligands for galectins is controlled in T cells by the availability of key metabolic intermediates [34]. Increasing $\beta 1,6 \mathrm{GlcNAc}-$ branched $\mathrm{N}$-glycans in T cells by hexosamine supplementation suppresses TCR signaling, 
CTLA-4 endocytosis, Th1 differentiation, and development of autoimmune inflammation [34] (Figure 2).

A critical process for dampening potential harmful T-cell responses is the fine-tuning of T-cell survival. Galectin-1, $-2,-3$ and -9 bind distinct cell surface glycoprotein receptors and trigger distinct intracellular signaling pathways to promote T-cell death [17,19,35-37]. Remarkably, a number of factors determine the responsiveness of cells to galectin-mediated signals which include the repertoire of glycosylated molecules expressed on the cell surface and the activities of specific glycosyltransferases, which are responsible for creating or masking galectin ligands $[5,6,18]$. These variables can dramatically change during thymic-development and peripheral activation and differentiation of $\mathrm{T}$ cells. [5,6,18,38-41].

Compelling evidence indicates that galectin-1 treatment suppresses chronic inflammation, modulates T-cell survival and skews the balance towards a Th2 cytokine profile in vitro [42] and in vivo in animal models, including experimental autoimmune uveitis [43] and autoimmune diabetes [44]. Furthermore, selective blockade of galectin-1 in tumor tissue results in increased Th1-mediated anti-tumor responses, suggesting potential involvement of this protein in tumorimmune escape [45]. Recent work provides a molecular explanation for galectin-1-mediated Th2 skewing, demonstrating that Th1 and Th17 effector cells express the repertoire of cell surface glycans that are essential for the formation galectin-glycoprotein lattices. In contrast $\mathrm{Th} 2$ cells are protected from galectin-1 binding through differential $\alpha 2,6$-sialylation of cell surface glycoproteins (Figure 2). Galectin-1-deficient mice consistently developed greater antigen-specific Th1 and Th17 responses compared to wild-type mice [40]. In addition, other galectin members may contribute to this immunoregulatory effect, including galectin- 9 which acts as a specific binding partner of Tim-3, a Th1-specific receptor, and selectively eliminates Th1 cells in vivo [46]. Furthermore, it has been proposed that phosphatidylserine exposure induced by galectins may serve as an alternative homeostatic mechanism, to favor phagocytosis, modulate secretion of anti-inflammatory cytokines and influence the resolution of inflammatory responses [47]. In contrast to the inhibitory actions of galectin-1, galectin-4 contributes to exacerbated intestinal inflammation by promoting $\mathrm{CD} 4^{+} \mathrm{T}$ cell activation and favoring IL-6 secretion through a protein kinase C $\theta$-dependent mechanism [48].

In addition to activation-induced cell death, avoidance of collateral damage to the host is also achieved by active immunosuppression mediated by regulatory $\mathrm{T}$ cells. We found that treatment with recombinant galectin- 1 in the efferent phase of autoimmune ocular inflammation results in increased IL-10 and TGF- $\beta$ production and expansion of regulatory $\mathrm{T}$ cells in vivo [43]. Interestingly, recent studies demonstrated that galectin-1 and -10 are overexpressed in regulatory $\mathrm{T}$ cells, and are critical for the suppressive activity of these cells [49, 50]. Further studies are needed to establish a role of galectin-carbohydrate lattices at synapse formation between regulatory and effector $\mathrm{T}$ cells.

\section{Galectin-glycoprotein lattices in B-cell functions}

VpreB, a surrogate immunoglobulin light chain that functions in early stages of B-cell receptor (BCR) maturation in pre-B cells, interacts with galectin-1 to modulate essential B-cell maturation activities [51]. An immune developmental synapse is formed between pre-B and stromal cells in a galectin-1-dependent manner: pre-BCR binding to stromal cells depends upon galectin-1 binding to glycosylated $\alpha_{4} \beta_{1}, \alpha_{5} \beta_{1}$, and $\alpha_{4} \beta_{7}$ integrins [51,52]. Pre-B cell integrins and their stromal cell ligands, together with pre-BCR and galectin-1, form a homogeneous lattice at the contact area between pre-B and stromal cells [52]. The resulting synapse formation initiates intracellular tyrosine kinase activity and signal transduction from the pre-BCR [51, 52]. In mature $B$ cells, the B cell-specific transcriptional coactivator OCA-B, important for B cell activation and germinal center formation, interacts with galectin-1. The authors showed that galectin-1 negatively regulates B-cell proliferation and tyrosine phosphorylation upon 
BCR stimulation [53]. Finally, anergic B cells show up-regulated expression of galectin-1 and -3 , suggesting a possible role for these lectins in the control of B-cell tolerance [54].

\section{Conclusions}

Research over the past few years has illuminated critical functions of galectin-glycoprotein lattices in receptor turnover and cell signaling, thus dictating the choice among cell proliferation, differentiation and survival, and serving as "on-an-off switch" that controls the decision between immune cell responsiveness and tolerance. Given the broad spectrum of immunoregulatory effects in autoimmune diseases and cancer, galectin-carbohydrate lattices are postulated as targets of novel anti-inflammatory and anti-cancer therapies. However, before galectin- or glycan-based therapeutic strategies can be fully realized, a more thorough understanding of the mechanisms by which galectin-carbohydrate lattices modulate cell function is required. To what extent is there functional redundancy and specificity of action within the galectin family? What is the precise explanation of the different functions exerted by the same galectin in different environmental contexts? What are the levels of galectins attained in vivo during an inflammatory reaction, infectious process or tumor dissemination? Increased understanding of the biochemistry and biology of galectin-glycoprotein lattices will provide insights into how the regulation of galectin expression and activity can be exploited for therapeutic purposes.

\section{Acknowledgements}

We thank members of the Rabinovich and Vasta laboratories for critical comments and discussion. We apologize to the many authors whose excellent papers could not be cited in this review for space limitations. Work in G.A.R's laboratory is supported by The Cancer Research Institute "Elaine R. Shepard Memorial Investigator", National Agency for Promotion of Science and Technology (PICT 2003-05-13787), University of Buenos Aires (M091), and a Program of Fundación Sales/CONICET. Work in G.R.V's laboratory is supported by grants R01 GM070589-01 from the National Institutes of Health, IOB 0618409 from the National Science Foundation, and NA05NMF4571243 from the National Oceanic and Atmospheric Administration. S.S.J. is supported by grant F32GM083352 from the National Institute of General Medical Sciences.

\section{References}

1. Miceli MC, Moran M, Chung CD, Patel VP, Low T, Zinnanti W. Co-stimulation and counterstimulation: lipid raft clustering controls TCR signaling and functional outcomes. Semin Immunol 2001;13:115-128. [PubMed: 11308295]

2. Cooper DN. Galectinomics: finding themes in complexity. Biochim Biophys Acta 2002;1572:209231. [PubMed: 12223271]

3. Liu FT, Rabinovich GA. Galectins as modulators of tumour progression. Nat Rev Cancer 2005;5:2941. [PubMed: 15630413]

4. Vasta GR, Ahmed H, Odom EW. Structural and functional diversity of lectin repertoires in invertebrates, protochordates and ectothermic vertebrates. Curr Opin Struct Biol 2004;14:617-630. [PubMed: 15465324]

5. Brewer CF, Miceli MC, Baum LG. Clusters, bundles, arrays and lattices: novel mechanisms for lectinsaccharide-mediated cellular interactions. Curr Opin Struct Biol 2002;12:616-623. [PubMed: 12464313]

6. Toscano MA, Ilarregui JM, Bianco GA, Campagna L, Croci DO, Salatino M, Rabinovich GA. Dissecting the pathophysiologic role of endogenous lectins: glycan-binding proteins with cytokinelike activity? Cytokine Growth Factor Rev 2007;18:57-71. [PubMed: 17321195]

7. Hirabayashi J, Hashidate T, Arata Y, Nishi N, Nakamura T, Hirashima M, Urashima T, Oka T, Futai M, Muller WE, et al. Oligosaccharide specificity of galectins: ra search by frontal affinity chromatography. Biochim Biophys Acta 2002;1572:232-254. [PubMed: 12223272]

8. Patnaik SK, Potvin B, Carlsson S, Sturm D, Leffler H, Stanley P. Complex N-glycans are the major ligands for galectin-1, -3 , and -8 on Chinese hamster ovary cells. Glycobiology 2006;16:305-317. [PubMed: 16319083] 
9. Dam TK, Gabius HJ, Andre S, Kaltner H, Lensch M, Brewer CF. Galectins bind to the multivalent glycoprotein asialofetuin with enhanced affinities and a gradient of decreasing binding constants. Biochemistry 2005;44:12564-12571. [PubMed: 16156668]

10. Lau KS, Partridge EA, Grigorian A, Silvescu CI, Reinhold VN, Demetriou M, Dennis JW. Complex $\mathrm{N}$-glycan number and degree of branching cooperate to regulate cell proliferation and differentiation. Cell 2007;129:123-134. [PubMed: 17418791] •• An elegant study showing a fine-tuning mechanism for switching from growth to arrest in cells based on the flux of UDP-GlcNAc through the Golgi and the extent of $\mathrm{N}$-glycan branching of growth factor receptors

11. Partridge EA, Le Roy C, Di Guglielmo GM, Pawling J, Cheung P, Granovsky M, Nabi IR, Wrana JL, Dennis JW. Regulation of cytokine receptors by Golgi N-glycan processing and endocytosis. Science 2004;306:120-124. [PubMed: 15459394]

12. Morris S, Ahmad N, Andre S, Kaltner H, Gabius HJ, Brenowitz M, Brewer F. Quaternary solution structures of galectins-1, -3, and -7. Glycobiology 2004;14:293-300. [PubMed: 14693909]

13. Ahmad N, Gabius HJ, Andre S, Kaltner H, Sabesan S, Roy R, Liu B, Macaluso F, Brewer CF. Galectin-3 precipitates as a pentamer with synthetic multivalent carbohydrates and forms heterogeneous cross-linked complexes. J Biol Chem 2004;279:10841-10847. [PubMed: 14672941]

14. Chen HY, Sharma BB, Yu L, Zuberi R, Weng IC, Kawakami Y, Kawakami T, Hsu DK, Liu FT. Role of galectin-3 in mast cell functions: galectin-3-deficient mast cells exhibit impaired mediator release and defective JNK expression. J Immunol 2006;177:4991-4997. [PubMed: 17015681]

15. Nieminen J, Kuno A, Hirabayashi J, Sato S. Visualization of galectin-3 oligomerization on the surface of neutrophils and endothelial cells using fluorescence resonance energy transfer. J Biol Chem 2007;282:1374-1383. [PubMed: 17082191] • An innovative study demonstrating the oligomerization of galectin-3 using fluorescence resonance energy transfer (FRET). The authors detected FRET signals during galectin-3-lattice formation on neutrophils and endothelial cells

16. Nieminen J, St-Pierre C, Sato S. Galectin-3 interacts with naive and primed neutrophils, inducing innate immune responses. J Leukoc Biol 2005;78:1127-1135. [PubMed: 16260586]

17. Stillman BN, Hsu DK, Pang M, Brewer CF, Johnson P, Liu FT, Baum LG. Galectin-3 and galectin-1 bind distinct cell surface glycoprotein receptors to induce T cell death. J Immunol 2006;176:778789. [PubMed: 16393961]

18. Daniels MA, Hogquist KA, Jameson SC. Sweet 'n' sour: the impact of differential glycosylation on T cell responses. Nat Immunol 2002;3:903-910. [PubMed: 12352967]

19. Hernandez JD, Nguyen JT, He J, Wang W, Ardman B, Green JM, Fukuda M, Baum LG. Galectin-1 binds different CD43 glycoforms to cluster CD43 and regulate T cell death. J Immunol 2006;177:5328-5336. [PubMed: 17015718]

20. Siebert HC, Andre S, Lu SY, Frank M, Kaltner H, van Kuik JA, Korchagina EY, Bovin N, Tajkhorshid E, Kaptein R, et al. Unique conformer selection of human growth-regulatory lectin galectin-1 for ganglioside GM1 versus bacterial toxins. Biochemistry 2003;42:14762-14773. [PubMed: 14674750]

21. Ohtsubo K, Takamatsu S, Minowa MT, Yoshida A, Takeuchi M, Marth JD. Dietary and genetic control of glucose transporter 2 glycosylation promotes insulin secretion in suppressing diabetes. Cell 2005;123:1307-1321. [PubMed: 16377570]•• The authors describe a novel mechanism, based on galectin-9-glycoprotein lattice formation, by which glycosylation controls cell-surface expression of the glucose transporter 2 (GLUT-2) on the surface of $\beta$-cells, providing a link among receptor glycosylation, glucose metabolism and insulin production

22. Park HJ, Partridge E, Cheung P, Pawling J, Donovan R, Wrana JL, Dennis JW. Chemical enhancers of cytokine signaling that suppress microfilament turnover and tumor cell growth. Cancer Res 2006;66:3558-3566. [PubMed: 16585180]

23. Lagana A, Goetz JG, Cheung P, Raz A, Dennis JW, Nabi IR. Galectin binding to Mgat5-modified N-glycans regulates fibronectin matrix remodeling in tumor cells. Mol Cell Biol 2006;26:3181-3193. [PubMed: 16581792]

24. Rabinovich GA, Gruppi A. Galectins as immunoregulators during infectious processes: from microbial invasion to the resolution of the disease. Parasite Immunol 2005;27:103-114. [PubMed: 15910418]

25. Pelletier I, Hashidate T, Urashima T, Nishi N, Nakamura T, Futai M, Arata Y, Kasai K, Hirashima M, Hirabayashi J, et al. Specific recognition of Leishmania major poly-beta-galactosyl epitopes by 
galectin-9: possible implication of galectin-9 in interaction between L. major and host cells. J Biol Chem 2003;278:22223-22230. [PubMed: 12684513]

26. Pelletier I, Sato S. Specific recognition and cleavage of galectin-3 by Leishmania major through species-specific polygalactose epitope. J Biol Chem 2002;277:17663-17670. [PubMed: 11882664]

27. Levroney EL, Aguilar HC, Fulcher JA, Kohatsu L, Pace KE, Pang M, Gurney KB, Baum LG, Lee B. Novel innate immune functions for galectin-1: galectin-1 inhibits cell fusion by Nipah virus envelope glycoproteins and augments dendritic cell secretion of proinflammatory cytokines. J Immunol 2005;175:413-420. [PubMed: 15972675]

28. Ouellet M, Mercier S, Pelletier I, Bounou S, Roy J, Hirabayashi J, Sato S, Tremblay MJ. Galectin-1 acts as a soluble host factor that promotes HIV-1 infectivity through stabilization of virus attachment to host cells. J Immunol 2005;174:4120-4126. [PubMed: 15778371]

29. Tasumi S, Vasta G. A galectin of unique domain organization from hemocytes of the eastern oyster (Crassostrea virginica) is a receptor for the protistan parasite Perkinsus marinus. J immunol. 2007In press

30. Fernandez GC, Ilarregui JM, Rubel CJ, Toscano MA, Gomez SA, Beigier Bompadre M, Isturiz MA, Rabinovich GA, Palermo MS. Galectin-3 and soluble fibrinogen act in concert to modulate neutrophil activation and survival: involvement of alternative MAPK pathways. Glycobiology 2005;15:519527. [PubMed: 15604089]

31. Barrionuevo P, Beigier-Bompadre M, Ilarregui JM, Toscano MA, Bianco GA, Isturiz MA, Rabinovich GA. A novel function for galectin-1 at the crossroad of innate and adaptive immunity: galectin-1 regulates monocyte/macrophage physiology through a nonapoptotic ERK-dependent pathway. J Immunol 2007;178:436-445. [PubMed: 17182582]

32. Demetriou M, Granovsky M, Quaggin S, Dennis JW. Negative regulation of T-cell activation and autoimmunity by Mgat5 N-glycosylation. Nature 2001;409:733-739. [PubMed: 11217864]

33. Morgan R, Gao G, Pawling J, Dennis JW, Demetriou M, Li B. N-acetylglucosaminyltransferase V (Mgat5)-mediated N-glycosylation negatively regulates Th1 cytokine production by T cells. J Immunol 2004;173:7200-7208. [PubMed: 15585841]

34. Grigorian A, Lee SU, Tian W, Chen IJ, Gao G, Mendelsohn R, Dennis JW, Demetriou M. Control of T cell mediated autoimmunity by metabolite flux to N-glycan biosynthesis. J Biol Chem. 2007

35. Fukumori T, Takenaka Y, Yoshii T, Kim HR, Hogan V, Inohara H, Kagawa S, Raz A. CD29 and CD7 mediate galectin-3-induced type II T-cell apoptosis. Cancer Res 2003;63:8302-8311. [PubMed: 14678989]

36. Lu LH, Nakagawa R, Kashio Y, Ito A, Shoji H, Nishi N, Hirashima M, Yamauchi A, Nakamura T. Characterization of galectin-9-induced death of Jurkat T cells. J Biochem (Tokyo) 2007;141:157172. [PubMed: 17167046]

37. Sturm A, Lensch M, Andre S, Kaltner H, Wiedenmann B, Rosewicz S, Dignass AU, Gabius HJ. Human galectin-2: novel inducer of $\mathrm{T}$ cell apoptosis with distinct profile of caspase activation. $\mathbf{J}$ Immunol 2004;173:3825-3837. [PubMed: 15356130]

38. Daniels MA, Devine L, Miller JD, Moser JM, Lukacher AE, Altman JD, Kavathas P, Hogquist KA, Jameson SC. CD8 binding to MHC class I molecules is influenced by T cell maturation and glycosylation. Immunity 2001;15:1051-1061. [PubMed: 11754824]

39. Hernandez JD, Klein J, Van Dyken SJ, Marth JD, Baum LG. T-cell activation results in microheterogeneous changes in glycosylation of CD45. Int Immunol 2007;19:847-856. [PubMed: 17606981]

40. Toscano MA, Bianco GA, Ilarregui JM, Croci DO, Correale J, Hernandez JD, Zwirner NW, Poirier F, Riley EM, Baum LG, et al. Differential glycosylation of $\mathrm{T}(\mathrm{H}) 1, \mathrm{~T}(\mathrm{H}) 2$ and $\mathrm{T}(\mathrm{H})-17$ effector cells selectively regulates susceptibility to cell death. Nat Immunol 2007;8:825-834. [PubMed: 17589510]

41. Comelli EM, Sutton-Smith M, Yan Q, Amado M, Panico M, Gilmartin T, Whisenant T, Lanigan CM, Head SR, Goldberg D, et al. Activation of murine CD4+ and CD8+ T lymphocytes leads to dramatic remodeling of N-linked glycans. J Immunol 2006;177:2431-2440. [PubMed: 16888005]

42. van der Leij J, van den Berg A, Harms G, Eschbach H, Vos H, Zwiers P, van Weeghel R, Groen H, Poppema S, Visser L. Strongly enhanced IL-10 production using stable galectin-1 homodimers. Mol Immunol 2007;44:506-513. [PubMed: 16581128] 
43. Toscano MA, Commodaro AG, Ilarregui JM, Bianco GA, Liberman A, Serra HM, Hirabayashi J, Rizzo LV, Rabinovich GA. Galectin-1 suppresses autoimmune retinal disease by promoting concomitant Th2- and $\mathrm{T}$ regulatory-mediated anti-inflammatory responses. J Immunol 2006;176:6323-6332. [PubMed: 16670344]

44. Perone MJ, Bertera S, Tawadrous ZS, Shufesky WJ, Piganelli JD, Baum LG, Trucco M, Morelli AE. Dendritic cells expressing transgenic galectin-1 delay onset of autoimmune diabetes in mice. $\mathrm{J}$ Immunol 2006;177:5278-5289. [PubMed: 17015713]

45. Rubinstein N, Alvarez M, Zwirner NW, Toscano MA, Ilarregui JM, Bravo A, Mordoh J, Fainboim L, Podhajcer OL, Rabinovich GA. Targeted inhibition of galectin-1 gene expression in tumor cells results in heightened T cell-mediated rejection; A potential mechanism of tumor-immune privilege. Cancer Cell 2004;5:241-251. [PubMed: 15050916]

46. Zhu C, Anderson AC, Schubart A, Xiong H, Imitola J, Khoury SJ, Zheng XX, Strom TB, Kuchroo VK. The Tim-3 ligand galectin-9 negatively regulates T helper type 1 immunity. Nat Immunol 2005;6:1245-1252. [PubMed: 16286920] • An innovative work identifying galectin-9 as a novel binding partner for Tim-3 and describing the relevance of this interaction in the regulation of Th1mediated autoimmune inflammation

47. Stowell SR, Karmakar S, Stowell CJ, Dias-Baruffi M, McEver RP, Cummings RD. Human galectin-1, -2 , and -4 induce surface exposure of phosphatidylserine in activated human neutrophils but not in activated T cells. Blood 2007;109:219-227. [PubMed: 16940423]

48. Hokama A, Mizoguchi E, Sugimoto K, Shimomura Y, Tanaka Y, Yoshida M, Rietdijk ST, de Jong YP, Snapper SB, Terhorst C, et al. Induced reactivity of intestinal CD4(+) T cells with an epithelial cell lectin, galectin-4, contributes to exacerbation of intestinal inflammation. Immunity 2004;20:681693. [PubMed: 15189734]

49. Garin MI, Chu CC, Golshayan D, Cernuda-Morollon E, Wait R, Lechler RI. Galectin-1: a key effector of regulation mediated by CD4+CD25+ T cells. Blood 2007;109:2058-2065. [PubMed: 17110462]

50. Kubach J, Lutter P, Bopp T, Stoll S, Becker C, Huter E, Richter C, Weingarten P, Warger T, Knop $\mathrm{J}$, et al. Human CD4+CD25+ regulatory T cells: proteome analysis identifies galectin-10 as a novel marker essential for their anergy and suppressive function. Blood. 2007• Recent studies demonstrating the contribution of galectins to the suppressive activity of $\mathrm{CD} 4{ }^{+} \mathrm{CD} 25^{+}$regulatory $\mathrm{T}$ cells

51. Gauthier L, Rossi B, Roux F, Termine E, Schiff C. Galectin-1 is a stromal cell ligand of the pre-B cell receptor (BCR) implicated in synapse formation between pre-B and stromal cells and in preBCR triggering. Proc Natl Acad Sci U S A 2002;99:13014-13019. [PubMed: 12271131]

52. Rossi B, Espeli M, Schiff C, Gauthier L. Clustering of pre-B cell integrins induces galectin-1dependent pre-B cell receptor relocalization and activation. J Immunol 2006;177:796-803. [PubMed: 16818733]• The authors describe the relevance of galectin-1-glycoprotein lattices in pre-B/stromal cell synapse formation, pre-BCR receptor segregation and activation

53. Yu X, Siegel R, Roeder RG. Interaction of the B cell-specific transcriptional coactivator OCA-B and galectin-1 and a possible role in regulating BCR-mediated B cell proliferation. J Biol Chem 2006;281:15505-15516. [PubMed: 16565088]

54. Clark AG, Chen S, Zhang H, Brady GF, Ungewitter EK, Bradley JK, Sackey FN, Foster MH. Multifunctional regulators of cell growth are differentially expressed in anergic murine B cells. Mol Immunol 2007;44:1274-1285. [PubMed: 16890292]

\section{Abbreviations \\ BCR}

B cell receptor

CRD

Carbohydrate recognition domain

CTLA-4

Cytotoxic T-lymphocyte-associated protein-4 


\section{EGFR}

Epidermal Growth Factor Receptor

FGFR

Fibroblast Growth Factor

FRET

Fluorescence resonance energy transfer

GLUT-2

Glucose transporter-2

IGFR

Insulin-like growth factor receptor

IL

Interleukin

LacNAc

$N$-acetyllactosamine

LPG

Lipophosphoglycan

GlcNAcT-IVa

$\mathrm{N}$-acetylglucosaminyltransferase IVa

GIcNAcT-V

$\mathrm{N}$-acetylglucosaminyltransferase V

MHC

Major histocompatibility complex

PDGFR

Platelet-derived growth factor receptor

TCR

$\mathrm{T}$ cell receptor

TGF- $\beta$

Transforming growth factor- $\beta$

TGF $\beta R$

Transforming growth factor- $\beta$ receptor

Th

T helper

Tim-3

T cell immunoglobulin mucin-3 


\section{A. Structure}
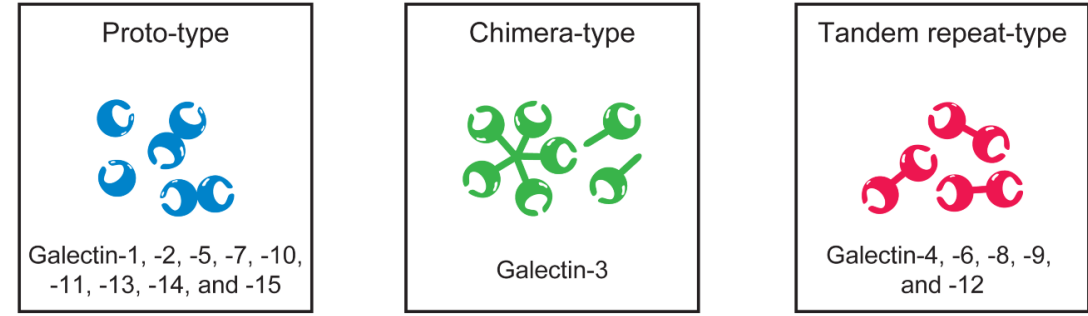

B. Galectin-carbohydrate lattices
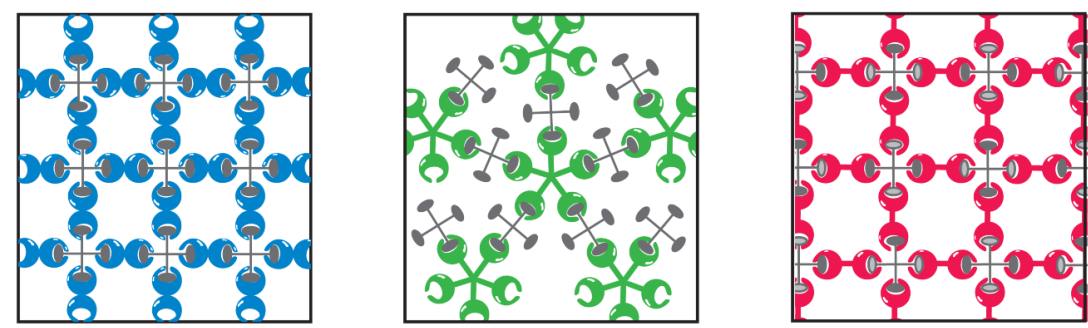

\section{Biological functions of galectin-glycoprotein lattices}

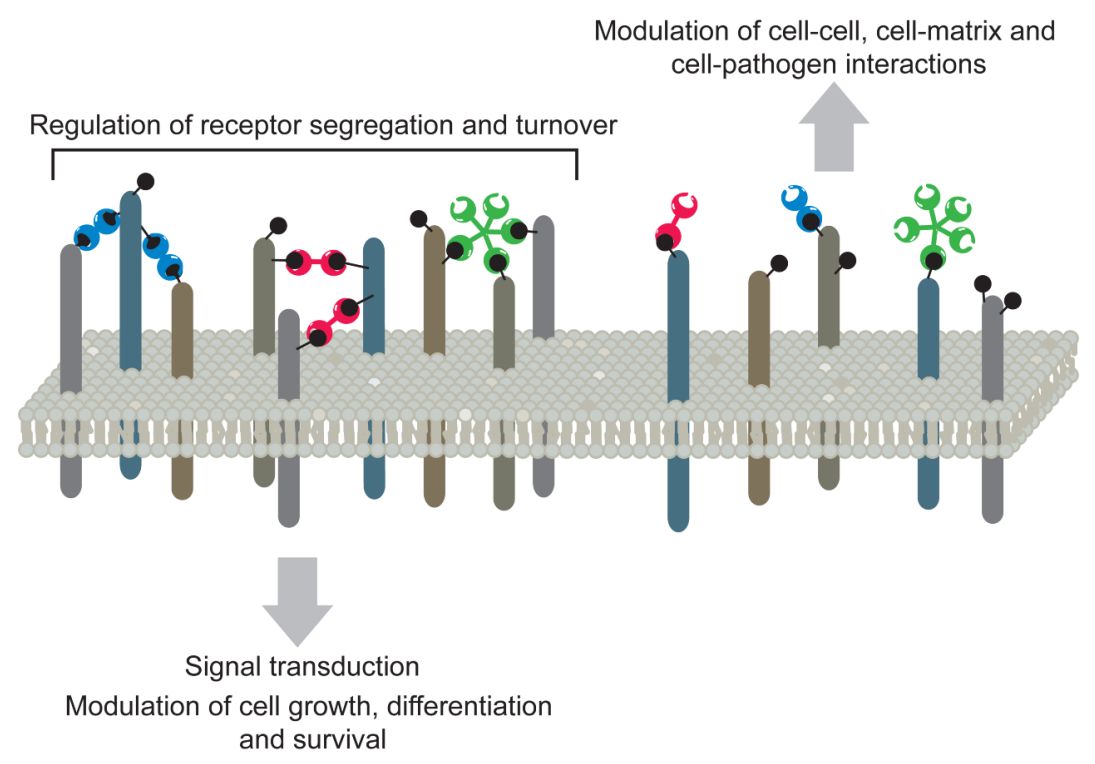

Figure 1. Biochemistry and functional relevance of galectin-glycoprotein lattices

(A) Schematic representation of the structure of different monomeric and oligomeric members of the galectin family. Proto-type galectins contain one CRD and exist in solution as homodimers. Chimera-type galectins are thought to undergo a conformational change following carbohydrate ligand binding which enables their oligomerization as pentamers. Tandem-repeat type galectins contain two distinct CRDs in tandem, connected by a linker of up to 70 amino acids, and are thus inherently dimeric. (B) Schematic representation of lattice formation between multivalent galectins and multivalent carbohydrate ligands. (C) Biological relevance of galectin-glycoprotein lattices. 


\section{A.}

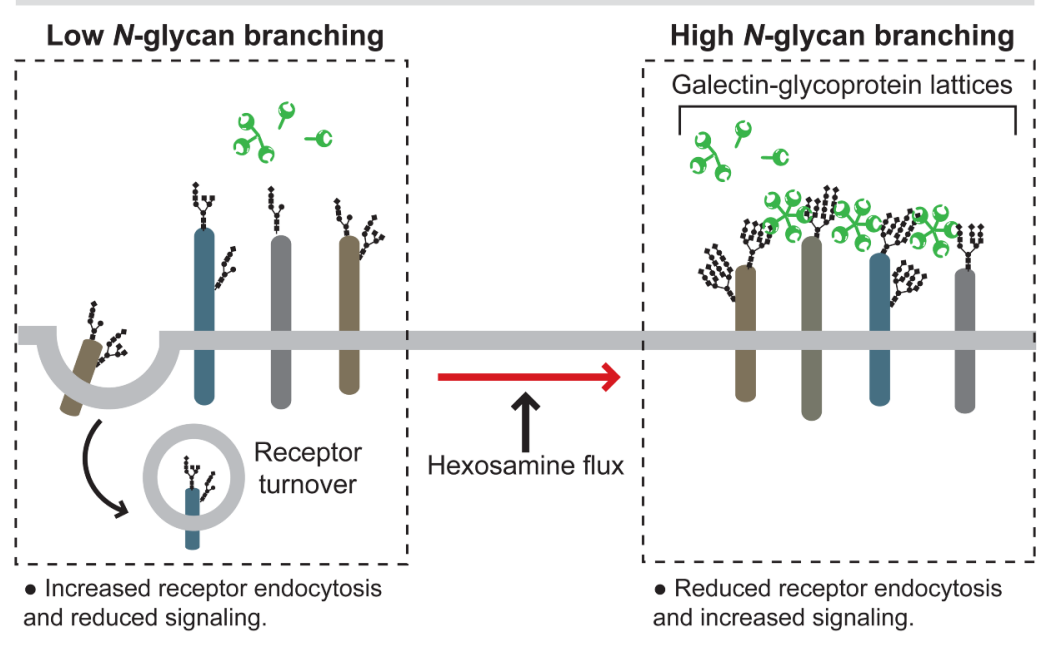

- Behavior of glycoproteins with

- Behavior of glycoproteins with low number of $\mathrm{N}$-glycan sites high number of $N$-glycan sites (growth-promoting receptors), or glycoproteins with low $\mathrm{N}$-glycan receptors in a high hexosamine

- Correlates with Mgat5- ${ }^{-1}$ T cells: Increased TCR lateral mobility and low TCR signaling threshold.

enviroment.

- Correlates with $\mathrm{Mgat5}^{+/+} \mathrm{T}$ cells: Reduced TCR lateral mobility and high TCR signaling threshold.

B.
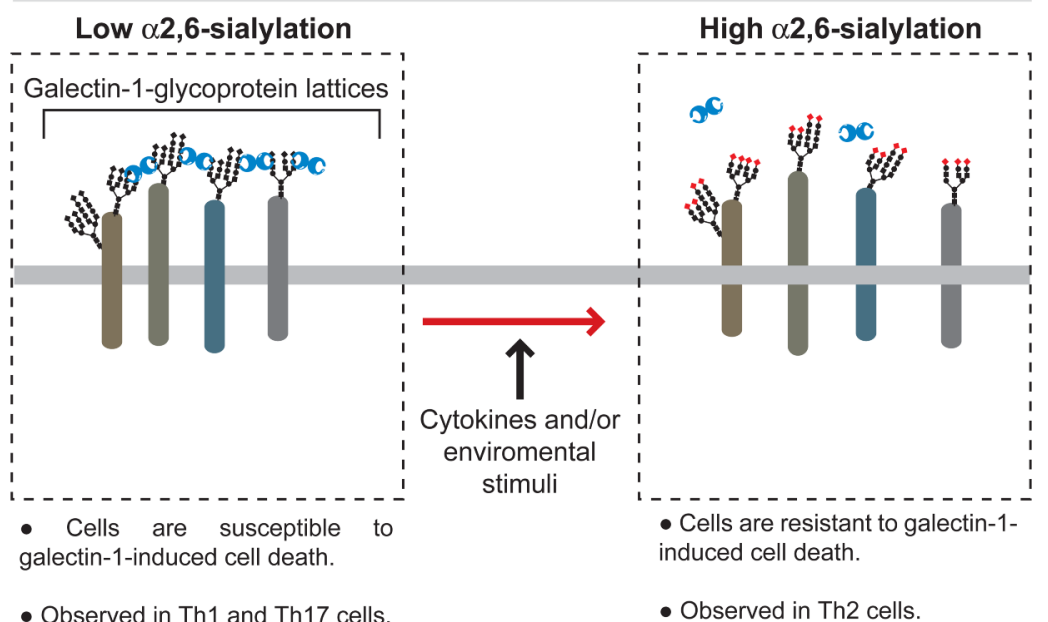

Figure 2. Galectin-glycoprotein lattices in the regulation of receptor turnover, cell signaling and survival

(A) The degree of $\mathrm{N}$-glycan branching controls galectin-glycoprotein lattice formation, which in turn modulates receptor turnover and signaling. (B) Differential sialylation of cell surface glycoproteins selectively influences the formation of galectin-glycoprotein lattices in distinct T-helper cells, thus regulating their susceptibility to galectin-1-induced cell death. 